\title{
Power Management of A Microgrid with A Distributed Energy Storage in Grid Connected and Islanded Modes
}

\author{
Wike Handini ${ }^{1}$, Hartono Budi Santoso ${ }^{1}$, Rudy Setiabudy ${ }^{1}$, and Eko Adhi Setiawan ${ }^{1}$
}

\begin{abstract}
Control and operation of a microgrid can be operated at grid connected or islanded modes. In this paper, the microgrid consists of a Diesel, PV modules with a distributed energy storage system, loads, and inverter. The purpose of power management is to control the stability of the system to cope with changes in load and interconnection with other networks. The stability of the microgrid is also obtained by setting the load connected to the system. Power management is also controls the operation of each plant based on the condition of the energy sources used as a source of generation. In islanded mode, the main goal of power management is to stabilize the system, in terms of frequency and voltage. In grid connected mode, typical objectives are to minimize the price of energy import at the point of common coupling (PCC).
\end{abstract}

Keywords-Power Management, PV-Diesel, Distributed Energy Storage, Microgrid.

\section{INTRODUCTION}

$\mathrm{T}$ echnology, economics, and the environment has changed the pattern of generation and distribution of electrical energy. Electric energy generation pattern has begun to change from a centralized pattern into distributed patterns. Microgrid is one of distributed generation pattern, which covers a wide range of energy sources, such as fossil sources and renewable energy sources (e.g. wind, solar, biogas, etc.). These sources are placed at customers sites. Differences in the characteristics of renewable energy sources and energy resource potential conditions become challenging to realize this idea.

Due to the limitations of economic and geographic conditions, centralized power distribution system have not been able to cover all areas that require electrical energy. By utilizing local renewable energy sources available in each region, microgrid can be used as a solution for areas not reached by electricity to create an energy independent region. Important matters of the microgrid is an interface and control for each of the energy sources that may exist in local, as well as voltage regulation, power flow, protection and stability operations.

The heart of the microgrid concept is the notion of a flexible, yet controllable interface between the microgrid and the wider power system. Depending on the type of Distributed Energy Resource (DER) units, load characteristics and power quality constraints, and market participation strategies, the required control and operational strategies of a microgrid can be different than those of the conventional power systems. The main reasons are as follows [9]:

a. steady-state and dynamic characteristics of DER units are different than the conventional large turbine-generator units

\footnotetext{
${ }^{1}$ Wike Handini, Hartono Budi Santoso, Rudy Setiabudy, and Eko Adhi Setiawan are with Departement of Electrical Engineering, Universitas Indonesia, Depok, Indonesia. E-mail: wike_handini@yahoo.com;hartono@esi-labs.com; rudy@eng.ui.ac.id; ekoas@ee.ui.ac.id.
}

b. a microgrid is inherently subject to a significant degree of imbalance due to the presence of singlephase loads and/or DER units

c. a noticeable portion of supply within a microgrid can be from noncontrollable sources

d. energy storage units can play a major role in control and operation of a microgrid

e. economics often dictate that a microgrid must readily accommodate connection and disconnection of DER units and loads while maintaining its operation

f. a microgrid may be required to provide prespecified power quality levels or preferential services to some loads

Microgrid is part of a major system that has the advantage of controlling their own, so if an interruption in the main system, microgrid still can perform the function of the generation and distribution to serve its own load. The microsources of special interest for microgrids are small units with power electronic interfaces. Power electronics provide the control and flexibility required by the microgrid concept. Correctly designed power electronics and controls insure that the microgrid can meet its customers as well as the utilities needs.

Microgrid are the systems that integrate distributed generation units, energy storage systems and controllable loads on a low voltage network which can operate in either grid-connected mode or stand-alone mode. These systems could be operated by means of a local management system with a communication infrastructure allowing control actions to be taken following any given strategy and objective. To the utility the microgrid can be thought of as a controlled cell of the power system. From the customer side of the interface, the microgrid should appear as an autonomous power system functioning optimally to meet the requirements of the customer, such as, enhance local reliability and quality of power.

As shown in Figure 1, the structure of microgrid consists of several types of DER (such as solar panels, wind turbines, microturbin, thermal power plant, etc.), each of which is a Distributed Generation (DG), and the Distributed Storage (DS). The Point of Common Coupling (PCC) is on the primary side of the transformer and defines the separation between the grid and the microgrid. 
Indonesia is an archipelago, thus causing some regions in Indonesia are not getting electricity which is provided by the government. This makes the development of microgrid system is an important alternative in the development of the electricity system. There are two main problems that can be answered with a microgrid. First, in remote areas, provision of electricity in the form of micro-networks can be easier and cheaper to do than building the construction of long distances transmission lines to access these remote areas. Second, in urban areas, provision of electricity in the form of micronetworks enable active involvement of consumers to meet the rising demand for electricity, so the burden of the state electricity company to hold additional supplies may be reduced.

One source of energy that can be used in microgrid system is solar power generation because the technology is more likely to be implemented in urban areas compared to wind turbines. Figure 2 shows the PV structure comprised of energy storage systems, such as batteries, along with the control module for battery charging and inverter module to generate the AC output voltage.

The battery charging control module responsible for managing the charging current to the battery or supply energy to the load directly from PV. At the time of the power generated by the solar panels is quite large, while the battery is fully charged, the power from the PV will directly supply the load. However, if the power generated from the PV could not meet load requirements, the BCR should be able to distributed energy from the battery to the load. If the energy in the battery is not able to meet the load demand, the BCR will disconnect the load.

The inverter module used to get AC power output to meet the AC load. The output voltage of the PV, battery and BCR is still in the form of a DC voltage, so it needs to be converted into $\mathrm{AC}$ voltage using an inverter to supply AC loads. If the inverter output only supply the load connected to the inverter, without being connected to the utility grid, the inverter is named off-grid inverter. However, if it is connected to the utility grid is called ongrid inverter.

A PV system alone cannot satisfy load on a 24-h basis. Often, the variations of solar energy generation don't match the time distribution of the demand. Therefore power generation systems recommend the association of energy storage facility. Electrical energy obtained from solar radiation, in addition to supplying the load are also stored in the energy storage systems such as batteries. Use of diesel system with PV-battery reduces battery storage requirement. The hybrid combination of PVdiesel-battery systems is a reliable source of electricity. Diesel energy is available all the time where as availability of PV is highly dependent on solar radiation.

\section{POWER MANAGEMENT SYSTEM}

To develop the distributed generation system based on renewable energy, power management is one of the most important problems to be resolved. Renewable energy sources like wind and solar radiation can not be predicted and uncontrollable causing power imbalances and quality concerns. The combination of renewable energy sources that have different characteristics also cause the system to become more complex and unpredictable. It is necessary to build the power management system which can easily be reconfigured for balancing the system by meeting the load demand, optimizing overall benefits and efficiency, and evaluating the system performance based on the best use of the multi energy sources.

\section{A. Multi Agent System}

Multi Agent Systems (MAS) can be used for power management system of microgrid. The MAS approach is adapted to model, control, manage or test the operations and management of microgrid. Agents represent individual entities in the network. Each participant is modeled as an autonomous participant with independent strategies and responses to outcomes. They are able to operate autonomously and interact pro-actively with their environment. Such characteristics of agents are best employed in situation like microgrid modeling.

Figure 3 shows the configuration of multi-agent systems in microgrid control system, in which the control mechanisms of the energy management system consists of load controllers (LC), and microgrid central controllers (MCC). Several microgrid is connected to the distributed network operator (DNO) and market operator (MO). Each of these controllers are agents that stand alone, which is able to process information and communicate among autonomous agents, depending on the purpose of the establishment of the overall system. The DNO is intended for an area in which more than one microgrid exists and responsible for the technical operation. MO is responsible for the market functions of each specific area. These two entities do not belong to the microgrid but are the delegates of the main grid.

Distributed control of microgrid, either a centralized or a decentralized supervisory control, has three hierarchical levels [9]:

a. DNO and MO at the level of the medium voltage

b. MCC

c. LC, which could be either micro source controllers or load controllers

The MCC is the main responsible for the optimization of the microgrid operation, or it simply coordinates the local controllers, which assume the main responsibility for this optimization. When connected to the power grid, MCCs follow the demands from the DNO and the LCs follow the command of the MCC. In islanded modes, MCC have the autonomy to perform local optimization of the micro source active and reactive power production, and load tracking following. The LCs control the DER, production and storage units, and some of the local loads. LCs are installed at the controllable loads to provide load control capabilities following demands from the MCC.

Multi agent system approach has several advantages over the traditional approaches for management and control of microgrid [25]. Some of the important advantages of the MAS approach are:

a. Unit autonomy

b. Reduced need for large data manipulation

c. Increased reliability and robustness of the control system:

d. Openness of the system 


\section{B. Power Sharing}

Power sharing on the source DC can be done by adjusting the magnitude of the voltage source from each source. Distribution of power in the parallel inverter is described in [27]. In a parallel multi-inverter system, each inverter acts as a voltage source. The difference between the output voltages of the paralleled inverters may make the output currents different, which may cause the severely unbalanced power sharing. To illustrate this phenomenon clearly, an equivalent circuit that includes two paralleled inverters is modeled, as shown in Figure 4 , where $\mathrm{U}_{1}, \mathrm{U}_{2}, \mathrm{I}_{1}$ and $\mathrm{I}_{2}$ represent the output voltage and current of the two inverters respectively, and $\mathrm{u}$, is the load voltage. $Z_{1}$ and $Z_{2}$ are the equivalent impedances of two inverters. For the convenience, assume that $\mathrm{Z}_{1}=\mathrm{Z}_{2}=\mathrm{Z}_{0}$. The load, which is represented as $\mathrm{Z}_{\mathrm{L}}$, can be of any type: resistive, inductive or capacitive.

There are several methods of power sharing have been developed, among others, the development of power sharing using PI controller to regulate the power supply from the plants [7]. Boost converters technology are used to match the voltages of the sources.

Another method is the development of power sharing using decentralized control system is based on measurement of the resistive output impedance of the inverters which are parallel connected in the DG system [11]. The controller consists on three nested loops:

a. the inner output voltage regulation loop,

b. the resistive output impedance loop, and

c. the P/Q sharing outer loop

A couple of topologies and control techniques were presented in [3]. Controller Area Network messages are used as the communication interfaces between key components and also as the interface with data monitoring system. Power sharing arrangements performed using the droop control method in each inverter. The development of power sharing using the droop control method also presented in [23]. Droop control based on the angle of the output voltage, referred to as angle droop.

Model and simulation of single phase PV inverters that work independently to supply three phase system as a part of renewable distributed generation were describes in [16]. This research uses two control methods, hysteresis current control and ramp comparison current control.

In [17], analysis is performed on the aspects of load sharing of a grid connected PV system and a strategy is proposed where the load sharing task can be undertaken controlling both modulation index and phase angle of the inverter. It is found that both real and reactive powers are affected upon change in modulation index and phase angle of the PV inverter.

Based on the reactive power controls adopted, three power management strategies are identified and investigated in [8]. These strategies are based on:

a. voltage-droop characteristic,

b. voltage regulation, and

c. load reactive power compensation.

The real power of each DG unit is controlled based on a frequency-droop characteristic and a complimentary frequency restoration strategy. The main criteria that should be met by the power management strategy are as follows: a. load sharing among DG units while minimizing the total power loss of the system;

b. consideration of specific limits of each DG unit, including type of theDGunit, cost of generation, timedependency of the prime source, maintenance interval, and environmental impacts;

c. maintaining the power quality inclusive of voltage profile, voltage fluctuations, and harmonic distortion;

d. improving the dynamic response, maintaining stabilitymargin, and voltage/frequency restoration of the system during and after transients.

\section{PROPOSED METHOD AND FUTURE WORK}

Microgrids consist of several basic technologies for operation, these include distributed generation, distributed storage, interconnection switches, and control systems. One of the technical challenges is the design, acceptance, and availability of low-cost technologies for installing and using microgrids.

The objectives of energy management depend on the mode of operation: Islanded, or grid-connected. In gridconnected mode, the loads in the microgrid receive power both from the grid and from the microsources depending on the customer's situation, typical objectives are to minimize the price of energy import at the PCC, to improve power factor at the PCC, and to optimize the voltage profile within the microgrid. In islanded mode, the microgrid is separated from the upstream distribution grid, the main goal of power management is to stabilize the system, in terms of frequency and voltage.

The major problem associated with the islanded mode is the service continuity, from whence the energy storage and the conventional sources (such as diesel) are required. The PV panels provide the maximum power to the load while the excess power required by the load is supplied by diesel.

Which will be carried out in this research is to develop an energy management system in the PV-diesel network with batteries distributed in each plant to be able to meet the loads, with a power sharing mechanism between plants in order to get the operating system is more stable and optimal. Configuration of the system to be developed can be seen in Figure 4.

Current Control (CC) is a power divider circuit that will regulate the amount of power that can be drawn from the battery. To avoid shortage of power supply to the load, the MCC will set the power limit of each distributed generation. MCC is an energy management system application that will calculate the power distribution of each plant.

CC is a DC-DC converter circuit programmed, which can set the value of the output voltage and output current limiting. CC had a buck boost topology, because it has a voltage input that approaches the battery voltage, and provide a voltage output voltage values around the nominal voltage of the battery as well, which is 12 Volt. To maintain the output voltage, $\mathrm{CC}$ equipped with current limiting circuit to keep the output power. CC operation settings using the microcontroller will generate PWM signals for DC-DC converter circuit.

MCC is a micro-processor based control devices. MCC is an energy management system applications that calculate the load sharing between plants, based on the load forecast data input parameters, and forecasts of 
solar radiation that is used to estimate the potential power of the PV. All these parameters are used for the optimization of load distribution and operation of diesel generators, to produce a stable and optimal microgrid.

Research to be done is to modeling a multi-agent system for energy management of microgrid in case of grid-connected mode and islanded mode, based on economical operation, and considering the load forecast and weather conditions. In grid connected mode, typical objectives are to minimize the price of energy import at the PCC. In islanded mode, the main goal of power management is to stabilize the system, in terms of frequency and voltage. To get there, that will be done first is to create a model of each component of the microgrid, which would be the agents. These models will form a unified system that will be used to create a simulation of the energy management system to achieve stability of the system on the microgrid.

\section{REFERENCES}

[1]. A. G. Tsikalakis, N. D. Hatziargyriou, "Centralized Control for Optimizing Microgrids Operation", IEEE Transactions on Energy Conversion, IEEE Journals, Vol. 23, No. 1, pp. 241-248, March 2008

[2]. A. L. Dimeas, N. D. Hatziargyriou, "A Multigent System for Microgrids", Power Engineering Society General Meeting, IEEE Conferences, Vol. 1, pp. 55-58, 2004

[3]. A. Tuladhar, "Power Management of an Off-Grid PV Inverter System with Generators and Battery banks", Power and Energy Society General Meeting, IEEE Conferences, pp. 1-5, 2011.

[4]. B. Kroposki, T. Basso, R. DeBlasio, "Microgrids Standards and Technologies", Power and Energy Society General Meeting Conversion and Delivery of Electrical Energy in the 21st Century, pp. 1-4, IEEE, 2008.

[5]. B. Lasseter, "Microgrids", Power Engineering Society Winter Meeting, Vol. 1, pp. 146-149, IEEE, 2001.

[6]. C. Marnay, F. J. Rubio, A. S. Siddiqui, "Shape of the Microgrid", Power Engineering Society Winter Meeting, Vol. 1, pp. 150-153, IEEE, 2001.

[7]. D. Yu, S. Yuvarajan, "Load Sharing in a Hybrid Power System with a PV Panel and a PEM Fuel-Cell", Applied Power Electronics Conference and Exposition, APEC '06. Twenty-First Annual IEEE, 2006.

[8]. F. Katiraei, R. Iravani, "Power Management Strategies for a Microgrid wirh Multiple Distributed Generation Units", IEEE Transactions on Power Systems, IEEE Journals, Vol. 21, No.4, pp. 1821-1831, November 2006.

[9]. F. Katiraei, R. Iravani, N. Hatziargyriou, A. Dimeas, "Microgrids Management", IEEE Power and Energy Management Magazine, Vol. 6, pp. 54-65, May/June 2008.

[10]. J. Lagorse, M. G. Simões, A. Miraoui, "A Multi-Agent Fuzzy Logic Based Energy Management of Hybrid System", IEEE Transactions on Industry Application, IEEE Journals, Vol. 45, pp. 2123-2129, 2009 .

[11]. J. M. Guerrero, N. Berbel, J. Matas, J. L. Sosa, J. Cruz, A. Alentorn, "Decentralized Control for Parallel Operation of
Distributed Generation Inverters Using Resistive Output Impedance", IEEE Transactions on Industrial Electronics, Vol. 54, No. 2, April 2007

[12]. J. Oyarzabal, J. Jimeno, J. Ruela, A. Engler, C. Hardt, "Agent Base Micro Grid Management System", IEEE Conferences, 2005.

[13]. J. R. B. Sousa, A. M. N. Lima, "Modeling and Simulation of Systems of Multiple Sources of Energy by Differential Hybrid Petri Nets", IEEE Conferences, pp. 1861-1866, 2008.

[14]. J. Zeng, H.W. Ngan, J. Liu, J. Wu, X. Yu, "Colored Petri Nets Modeling of Multi-agent System for Energy Management in Distributed Renewable Energy Generation System", IEEE Conferences, pp. 1-5, 2010.

[15]. L. Wang, Q. Chen, "Power Grid Fault Diagnosis Model Based on Fault Knowledge Representation", IEEE Conferences, pp. 539-543, 2011.

[16]. M. I. Hamid, M. Anwari, Z. Salam, Taufik, "Load Sharing Characteristic of Single Phase PV Inverter Connected to Grid", 2nd IEEE International Conference on Power and Energy (PECon 08), December 1-3, Johor Bahru, Malaysia, 2008.

[17]. M. Quamruzzaman, K. M. Rahman, "Development of Control Strategy for Load Sharing in Grid-Connected PV Power System", 5th International Conference on Electrical and Computer Engineering ICECE Dhaka, Bangladesh, 20-22 December 2008.

[18]. N. D. Hatziargyriou, A. L. Dimeas, A. G. Tsikalakis, J. A. P. Lopes, G. N. Kariniotakis, J. Oyarzabal, "Management of Microgrids in Market Environment", IEEE Conferences, 2005.

[19]. Q. Jiang, M. Xue, G. Geng, "Energy Management of Microgrid in Grid-Connected and Stand-Alone Modes", IEEE Trans. on Power Systems, Vol. 28, Issue: 3, pp. 3380-3389, 2013.

[20]. R. H. Lasseter, "MicroGrids", Power Engineering Society Winter Meeting, Vol. 1, pp. 305-308, IEEE, 2002.

[21]. R. Lasseter, A. Akhil, C. Marnay, J. Stephens, J. Dagle, R. Guttromson, A. Sakis Meliopoulous, R. Yinger, and J. Eto, "Integration of Distributed Energy Resources - The CERTS MicroGrid Concept", CERTS, April 2002.

[22]. R .Lukomski, K. Wilkosz, "Modeling of Multi-agents System for Power System Topology Verification with use of Petri Nets", IEEE Conferences, pp. 1-6, 2010.

[23]. R. Majumder, B. Chaudhuri, A. Ghosh, R. Majumder, G. Ledwich, F. Zare, "Improvement of Stability and Load Sharing in an Autonomous Microgrid Using Supplementary Droop Control Loop", IEEE Transactions on Power Systems, IEEE Journals, Vol. 25, No. 2, pp. 796-808, May 2010.

[24]. S. H. Lee, G. T. Son, J.-W. Park, "Power Management and Control for Grid-Connected DGs with Intentional Islanding Operation of Inverter", IEEE Transactions on Power Systems, IEEE Journals, Vol. 28, pp. 1235-1244, 2013.

[25]. T. Logenthiran, D. Srinivasan, D. Wong, "Multi-Agent Coordination for DER in MicroGrid", Sustainable Energy Technologies, ICSET 2008, IEEE Conferences, pp. 77-82, 2008.

[26]. T. S. Ustun, C. Ozansoy, A. Zayegh, "Distributed Energy Resource (DER) Object Modeling with IEC 61850-7-420", Universities Power Engineering Conference (AUPEC), 2011 21st Australasian, IEEE Conferences, pp. 1-6, 2011.

[27]. Y. Sun, W. Qu, B. Liang, "An Advanced Synchronization and Current-sharing Method for Paralleled DC/AC Inverters withou Interconnection", Proceedings of the Eighth International Conference on Electrical Machines and Systems, ICEMS, 2005.

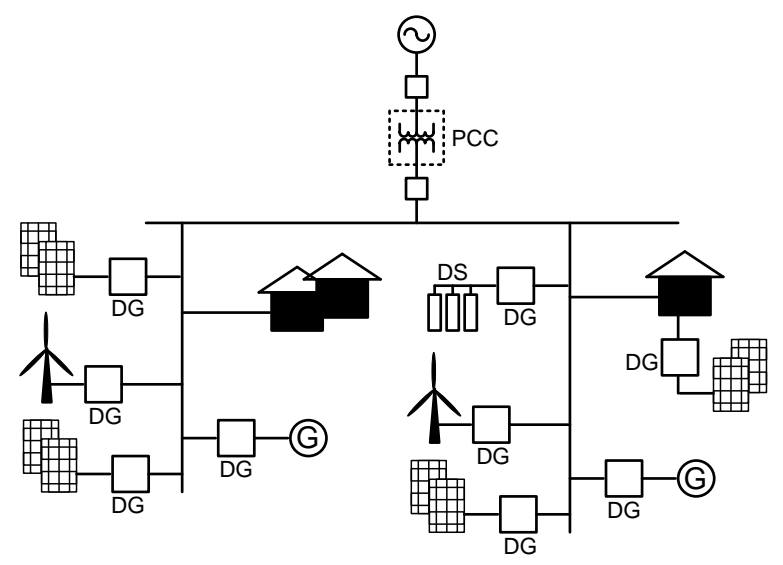

Figure. 1. Microgrid Architecture 


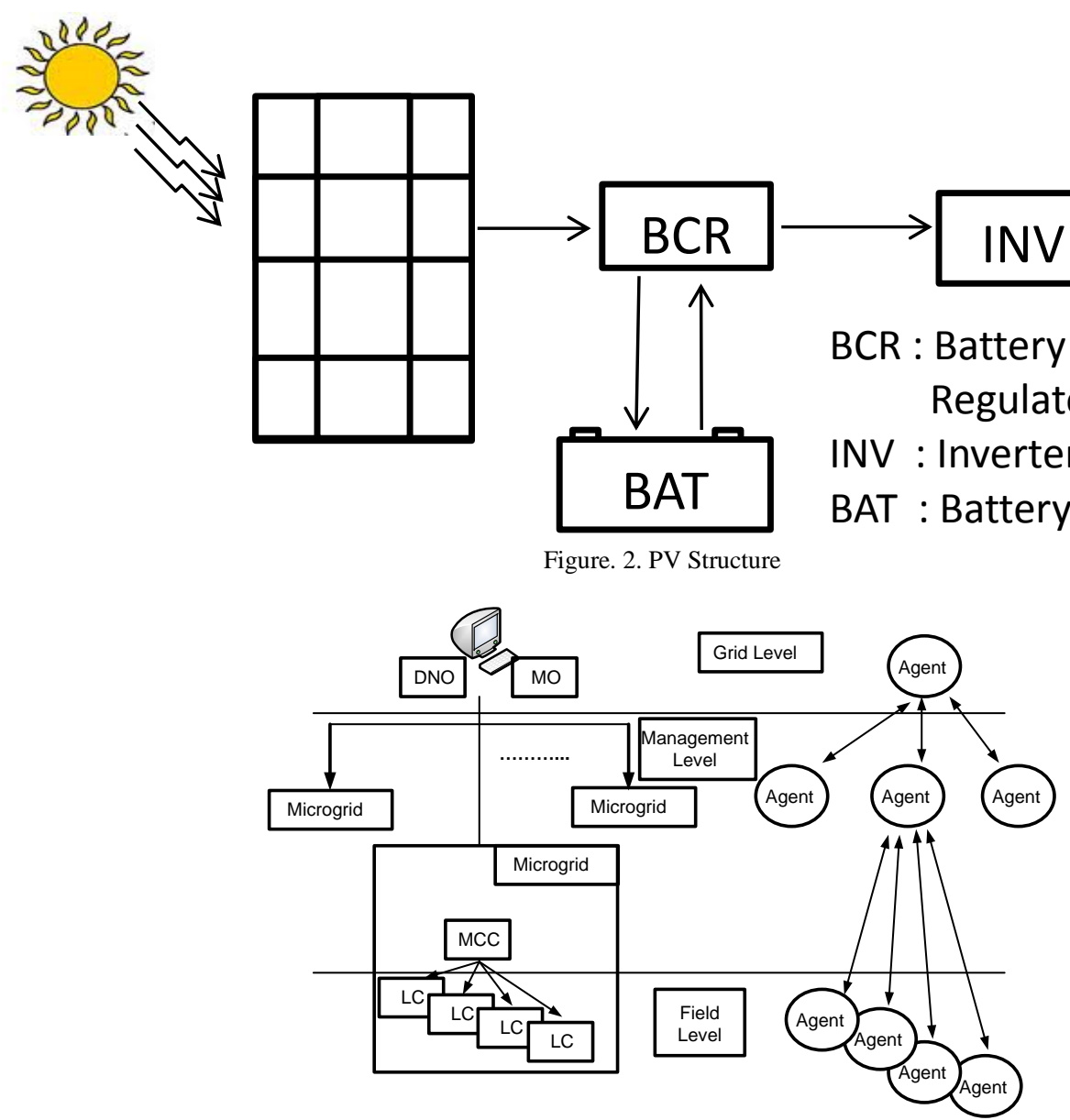

Figure. 3. Multi Agent Systems Configuration in Microgrid Control Management

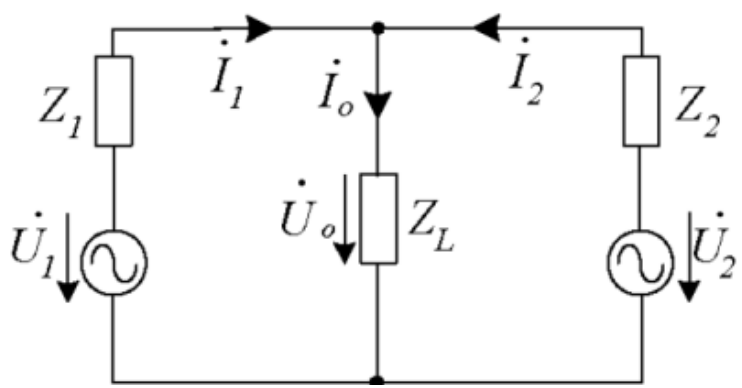

Figure. 4. The equivalent circuit of two paralleled inverters

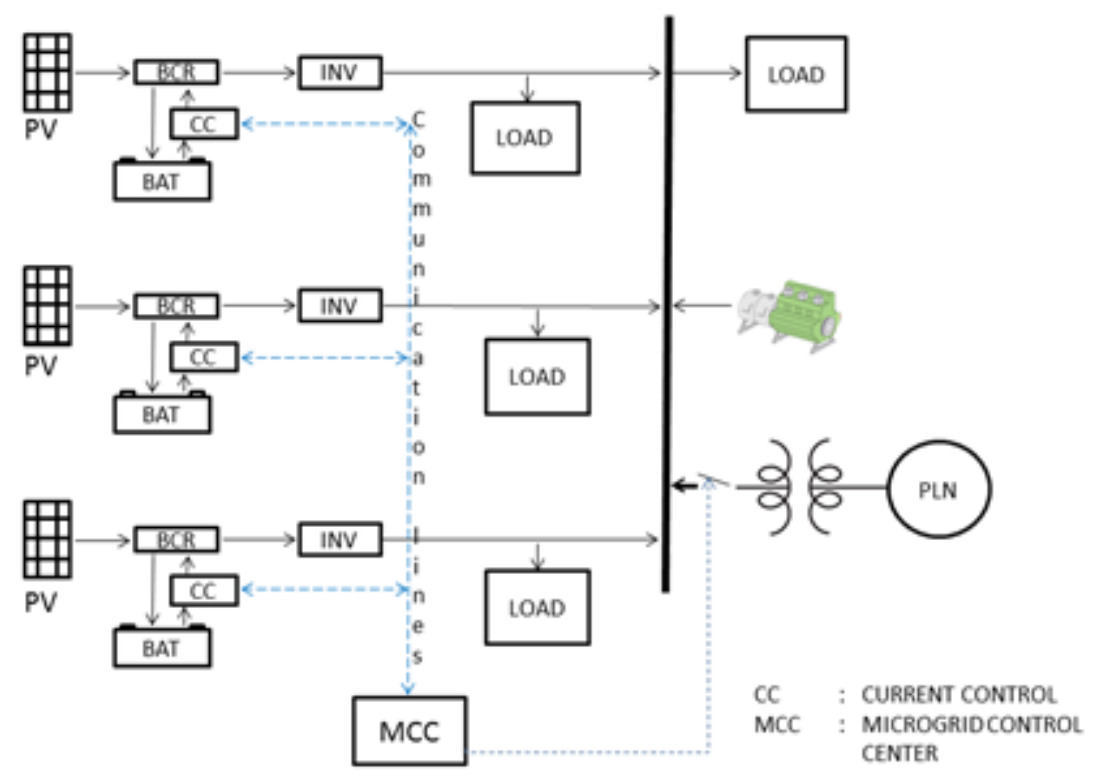

Figure. 4. System Configuration for Energy Management System Development Research 